\title{
TELECOMMUNICATION SYSTEMS AND NETWORKS
}

\author{
DOI 10.20535/2411-1031.2019.7.2.190572 \\ УДК 621.396
}

\author{
В’ЯЧЕСЛАВ СОЛОДОВНИК, \\ МИКОЛА НАУМЕНКО
}

\section{МЕТОД ПРОСТОРОВО-ЧАСТОТНОГО БЛОЧНОГО КОДУВАННЯ СИГНАЛІВ 3 ДВОРЕЖИМНОЮ ІНДЕКСНОЮ МОДУЛЯЦІЕЮ ПІДНЕСУЧИХ ОFDМ}

Розглянуто технологію сумісного застосування багатоантенних систем МIMO та ортогонального частотного розподілу каналів з мультиплексуванням OFDM для сучасних систем безпроводового зв'язку. Показано, що традиційні шляхи підвищення спектральної та енергетичної ефективності таких систем вичерпали себе через частотно-енергетичнопросторову обмеженість безпроводового каналу зв'язку. Визначено ключові обмеження щодо застосування великої кількості антен, що пов'язані з вимогами до масо-габаритних показників мобільних терміналів та необхідністю забезпечення мінімального рівня просторової кореляції завмирань між сигналами. Показано, що фазова нестаціонарність сигналів $\epsilon$ основною причиною міжканальної інтерференції, що зменшує ефективність модуляції OFDM. Визначено області пріоритетного використання часового та частотного варіантів рознесеної передачі сигналів за принципом Аламоуті для безпроводових каналів зв'язку з обмеженими частотними та енергетичними ресурсами. Проаналізовано концепцію індексної модуляції та зазначено, що метод індексної модуляції піднесучих OFDM-IM $€$ найбільш перспективним засобом підвищення завадостійкості та швидкості передачі інформації для реальних частотно-селективних каналів систем безпроводового зв'язку. Продемонстровано переваги подвійного режиму (Dual-Mode) OFDM-IM 3 оптимізованими ансамблями сигналів на базі BPSK, QPSK та 16-QAM. Запропоновано нову сигнально-кодову конструкцію із об’єднанням дворежимної індексної модуляції піднесучих OFDM та ортогонального просторово-частотного блочного кодування 3 ядром Аламоуті SFBC-DM-OFDM-IM. Такий метод у порівнянні 3 класичним SFBC-OFDM дозволяє одночасно підвищити спектральну та енергетичну ефективність систем передачі інформації в умовах впливу частотно-часової селективності безпроводового каналу зв'язку. Метод SFBCDM-OFDM-IM доцільно використовувати для забезпечення якісного зв'язку 3 високодинамічними наземними об'єктами, безпілотними та іншими літальними апаратами при критичному зменшенні співвідношення сигнал/шум, що має місце при впливові засобів радіоелектронного подавлення. Отримані наукові результати можуть ефективно використовуватися для проектування мереж безпроводового зв'язку нового покоління в умовах обмеженості частотно-енергетичних ресурсів.

Ключові слова: просторово-частотне блочне кодування, MIMO, OFDM, індексна модуляція, подвійний режим, нестаціонарність.

Постановка проблеми. Однією з основних вимог до сучасних систем безпроводового зв'язку (СБ3) є підтримка об'ємних інформаційних мультимедійних застосунків із забезпеченням високих показників завадостійкості та швидкості передачі інформації. В умовах впливу засобів радіоелектронного подавлення (РЕП), коли шумова захищеність каналів зв'язку (КЗ) критично знижується, ефективність використання КЗ повинна наближатись практично до теоретичних меж. В умовах складної завадової обстановки високоефективне використання реальних безпроводових КЗ суттєво ускладнюється через їх частотну селективність та нестаціонарну поведінку, а також обмеженість частотноенергетичних та просторових ресурсів. 
На теперішній час найбільш продуктивним методом забезпечення високої інформаційної, енергетичної (ЕE) та спектральної ефективності (CE) сучасних СБЗ $є$ технологія одночасного застосування багатоантенних систем (Multiple Input-Multiple Output, MIMO) та мультиплексування 3 ортогональним частотним розподілом каналів (Orthogonal Frequency Division Multiplexing, OFDM). Технологія MIMO дає можливість суттєво підвищити ЕЕ та/або СЕ, базуючись на методах ортогонального, квазіортогонального та неортогонального просторово-часового блочного кодування сигналів (Space-Time Block Coding, STBC). Модуляція за схемою OFDM характеризується низьким рівнем міжсимвольної інтерференції (Inter-Symbol Interference, ISI).

Ефективність MIMO залежить від кількості передавальних та приймальних антен. Основними обмеженнями щодо застосування великої кількості антен $є$ вимоги до компактності мобільних терміналів, а також забезпечення мінімального рівня просторової кореляції завмирань між сигналами. Слід зауважити, що значний рівень просторової кореляції призводить до зменшення пропускної спроможності КЗ та здатний звести до нуля всі переваги MIMO [1], тому кількість антенних елементів на прийомі/передачі в сучасних стандартах безпроводового зв'язку найчастіше не перевищує двох-чотирьох (іноді - восьми). Недоліком OFDM є міжканальна інтерференція (Inter-Channel Interference, ICI), причиною якої $є$ порушення ортогональності піднесучих через фазову нестаціонарність сигналів внаслідок відносної нестабільності частоти задаючих генераторів, доплерівського зсуву частот (ДЗЧ) та інших випадкових фазових флуктуацій сигналів.

3 урахуванням наведених переваг та завдяки можливості ефективного управління частотно-енергетичним ресурсом, технологія MIMO-OFDM $є$ невід'ємною частиною практично всіх стандартів безпроводового зв'язку: Long-Term Evolution (LTE) i LTE-Advanced (LTE-A), IEEE 802.16 WiMAX та IEEE $802.11 \mathrm{a} / \mathrm{g} / \mathrm{n} \mathrm{Wi-Fi} \mathrm{[2]} \mathrm{-} \mathrm{[4].} \mathrm{Найбільш}$ широкого застосування знайшов метод ортогонального STBC для двох передавальних антен $T x$, відомий як схема Аламоуті [5]. Головними перевагами такої схеми є:

a) забезпечення повного рознесення сигналів $(2 \times R x$, де $R x$ - кількість приймальних антен);

б) максимальна швидкість просторового коду, що дорівнює одиниці;

в) лінійна складність декодера максимальної правдоподібності (Maximum Likelihood, ML).

Дослідження показали, що метод STBC-OFDM [6], [7] є стійким до частотної селективності каналу, однак у нестаціонарних умовах внаслідок порушення умови квазістаціонарності каналу на тривалості просторово-часового кодового слова завадостійкість такого методу суттєво погіршується.

Більш стійкою до нестаціонарної поведінки каналу є частотна версія коду Аламоуті (Space-Frequency Block Coding, SFBC), що також використовується в сучасних стандартах безпроводового зв'язку на лінії “вниз” та передбачає передачу сигналів на парах суміжних піднесучих [1], [7], [8]. Однак завадостійкість методу SFBC-OFDM швидко втрачається у каналах зі зростаючим рівнем частотної селективності.

Обидва варіанти рознесеної передачі сигналів за принципом Аламоуті (часовий (STBC) та частотний (SFBC)) мають мінімальну довжину кодового слова (складається 3 двох сигнальних елементів), що позитивно впливає на забезпечення квазістаціонарності каналу в умовах частотно-часової селективності. Більш того, метод STBC з ядром Аламоуті при $T x \times R x=2 \times 1$ дозволяє практично наполовину наблизити завадостійкість релеївського каналу до потенційної завадостійкості гаусівського каналу, а при $2 \times 2$ - досягається майже така ж ефективність як і в гаусівському каналі. Однак методи STBC та SFBC 3 ядром Аламоуті потребують удосконалення як в частині підвищення CE, так і EE, насамперед, при низьких співвідношеннях сигнал/шум (Signal-to-Noise Ratio, SNR), що мають місце при інтенсивній роботі засобів постановки навмисних завад.

Традиційні шляхи підвищення СЕ та ЕE, пов’язані зі збільшенням швидкості модуляції, об’єму ансамблю сигналів, кількості антен та потужності випромінювання, вичерпали себе 
через частотно-енергетично-просторову обмеженість безпроводового КЗ. Збільшити швидкість передачі цифрової інформації можливо завдяки введенню додаткових сигнальних вимірів, що забезпечують формування та передачу певної частини інформаційних біт шляхом реалізації неявного інформаційно-керованого механізму перемикання стану активності допоміжних блоків передачі.

Аналіз останніх досліджень і публікацій. За останнє десятиліття розроблено широкий клас схем з індексною модуляцією (Index Modulation, IM) [9] - [12], в яких інформаційні біти можуть приєднуватись до різних фізичних або віртуальних блоків трансляції. Таким чином, індексна модуляція - це методи передачі інформації, що полягають у поділі інформаційних біт на індексні та біти символів ансамблю сигналів 3 подальшою активацією елементів блоків, що передають ці символи. Оскільки метод OFDM став практично безальтернативним способом боротьби з ISI, тому для класу частотно-селективних каналів найбільш ефективним $\epsilon$ метод індексної модуляції піднесучих OFDM (OFDM-IM) [13] - [15], що дозволяє одночасно підвищити завадостійкість та швидкість передачі інформації за рахунок введення додаткового частотного виміру сигналів.

У [16], [17] запропоновано сигнально-кодову конструкцію (СКК) із об'єднанням індексної модуляції піднесучих OFDM та просторово-часового блочного кодування STBC-OFDM-IM, що дозволяє отримати енергетичний виграш (EB) до 8 дБ при ймовірності бітової помилки $P_{n o м}=10^{-5}$ у порівнянні з класичним STBC-OFDM, або підвищити СЕ до $20 \%$ при ЕВ до 5 дБ, при $15<S N R<25$ дБ, що становлять практичний інтерес в сучасних СБ3. Слід зауважити, що за умови використання базових та основних для СБЗ багатопозиційних комплексних ансамблів сигналів з фазовою (Phase Shift Keying, M-PSK) або квадратурно-амплітудною модуляцією (Quadrature Amplitude Modulation, M-QAM) 3 $M=2,4,16$, зазначені результати ЕЕ та СЕ можуть бути покращені на 5 дБ при BPSK (Binary PSK, $M=2$ ), 2 дБ - при QPSK (Quadrature PSK, $M=4$ ) і на 1 дБ - при 16-QАМ з одночасним додатковим підвищенням показників СЕ на 20\%, 17,6\% і 12,5\% для BPSK, QPSK та 16-QAM відповідно, завдяки застосуванню методу дворежимного (Dual Mode) OFDM-IM (DM-OFDM-IM) з удосконаленими структурами комплексного ансамблю сигналів та способу упаковки біт, запропонованих у [18].

У [19], [20] запропоновано СКК, побудовану на основі сумісного застосування ортогонального STBC та дворежимної індексної модуляції STBC-DM-OFDM-IM. У порівнянні з однорежимним методом STBC-OFDM-IM, запропонована дворежимна СКК дає ЕВ до 4,7 дБ при $P_{n o м}=10^{-5}$ з одночасним підвищенням СЕ до 5-20\% для ансамблів сигналів невеликого об'єму ( $M \leq 16)$. Слід зазначити, що ефективність цих методів [16], [17], [19], [20] зменшується при негативному впливі ДЗЧ, оскільки складові таких СКК - STBC та OFDM - є критичними до нестаціонарної поведінки каналу.

Для забезпечення якісного зв'язку з високодинамічними об'єктами важливо розробити CKК на базі методу SFBC, що $є$ потенційно стійким до неінваріантних у часі статистичних параметрів каналів.

Метою статті є підвищення спектральної та енергетичної ефективності методу просторово-частотного блочного кодування SFBC з використанням концепції дворежимної індексної модуляції піднесучих OFDM для нестаціонарних частотно-селективних каналів систем безпроводового зв'язку.

Виклад основного матеріалу дослідження. Узагальнена структурна схема технології SFBC-DM-OFDM-IM представлена на рис. 1. Для простоти викладення змісту досліджень розглядається прийом сигналів на одну антену $(R x=1)$. Отримані результати легко узагальнюються для випадку, коли $R x>1$.

Загальна вхідна послідовність із $m$ інформаційних біт після послідовно-паралельного перетворення (Serial-to-Parallel, $\mathrm{S} / \mathrm{P}$ ) розподіляється на $G$ груп по $p=p_{1}+p_{2}$ біт, тобто

$$
m=p G=\left(p_{1}+p_{2}\right) G,
$$


де $p_{1}=\left\lfloor\log _{2}\left(C\left(\begin{array}{l}N \\ K\end{array}\right)\right)\right\rfloor-$ біти, що використовуються для визначення $K$ піднесучих, які модулюються символами ансамблю сигналів $\mathbf{D}\left(M_{A}\right)$ типу $A$ розміром $M_{A}$ у кожному субблоці DM-OFDM-IM довжиною $N=N_{F} / G$;

$N_{F}$ - загальна кількість піднесучих OFDM - розмір вікна зворотного швидкого перетворення Фур'є (Inverse Fast Fourier Transform, IFFT);

$\lfloor x\rfloor=\max \{a \in Z \mid a \leq x\}, \mathbf{Z}$ - множина цілих чисел;

$C\left(\begin{array}{l}N \\ K\end{array}\right)$ - кількість комбінацій із $N$ по $K$. Решта $(N-K)$ піднесучих модулюються символами ансамблю сигналів $\mathbf{D}\left(M_{B}\right)$ типу $B$ розміром $M_{B}$.

Таким чином, $p_{2}=p_{2, A}+p_{2, B}=K \log _{2} M_{A}+(N-K) \log _{2} M_{B}$. Слід зазначити, що для надійного детектування індексних біт при обмеженні на однаковий розмір ансамблів сигналів $\left(M_{A}=M_{B}=M\right)$, необхідно забезпечити можливість їх розрізняти: $M_{A} \cap M_{B}=\varnothing[21]$.

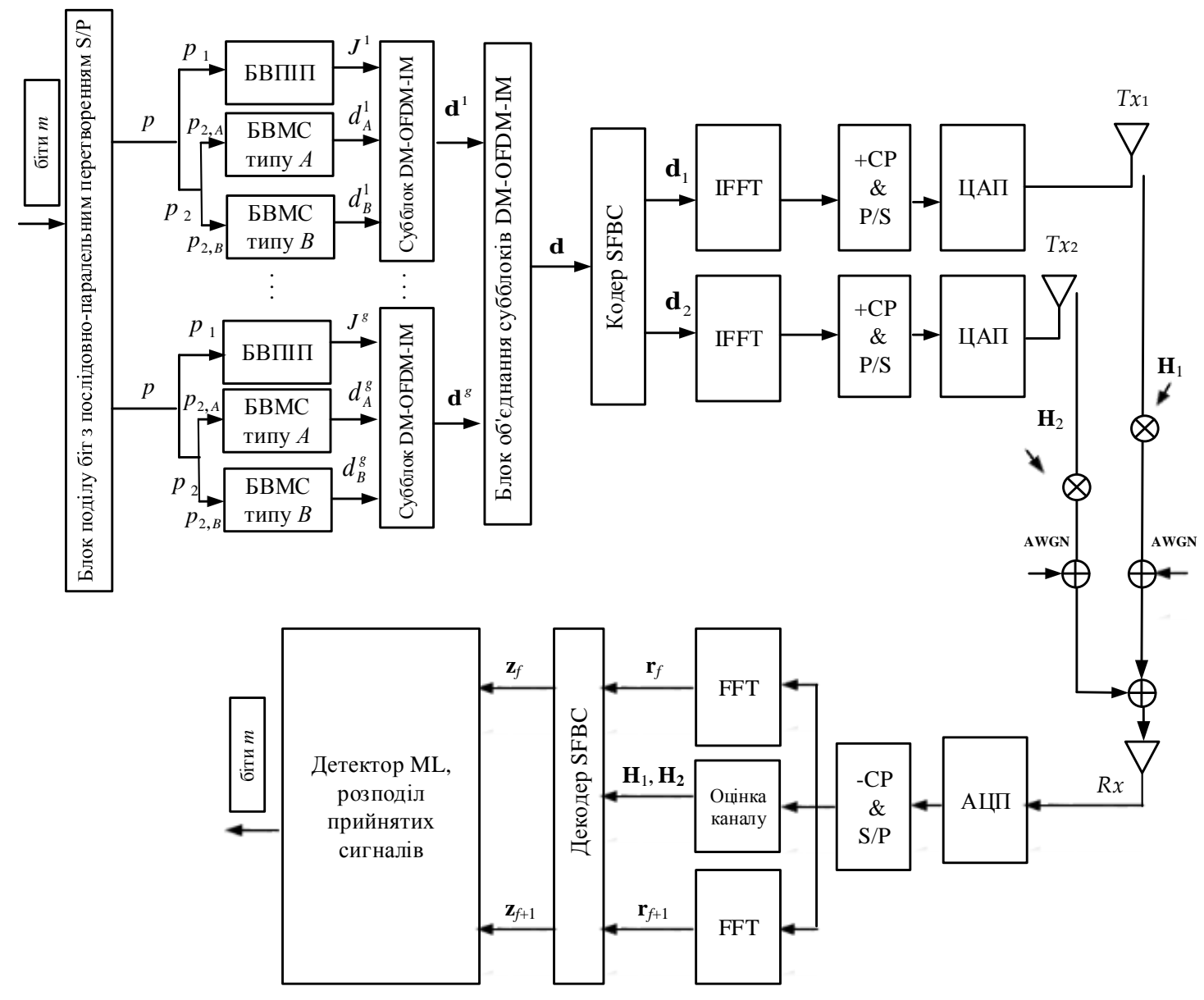

Рисунок 1 - Структурна схема SFBC-DM-OFDM-IM $2 \times 1$

Процедура визначення $K$ піднесучих, які модулюються символами ансамблю сигналів типу $A$, та $(N-K)$ піднесучих - типу $B$, здійснюється на основі таблиць асоціативності (Reference Look-up Tables, RLUT), що дозволяє реалізацію оптимального ML-декодера при невеликих розмірах субблоків $N \leq 8$ [13], [21]. 
На виході блоків визначення піднаборів індексів піднесучих (БВПІП) формуються послідовності

$$
\begin{aligned}
& J_{A}^{g}=\left\{j_{A}^{g}(1), \ldots, j_{A}^{g}(K)\right\} ; j_{A}^{g}(k) \in\{1, \ldots, N\} ; k=1, \ldots, K ; g=1, \ldots, G ; \\
& J_{B}^{g}=\left\{j_{B}^{g}(1), \ldots, j_{B}^{g}(N-K)\right\} ; j_{B}^{g}(l) \in\{1, \ldots, N-K\} ; l=1, \ldots, N-K .
\end{aligned}
$$

Важливо зауважити, що послідовність $J_{A}^{g}$ є основою для визначення структури $J_{B}^{g}$.

Блоки вибору модуляційних символів (БВМС) ансамблів $\mathbf{D}\left(M_{A, B}\right)$ із урахуванням (2) визначають послідовності з $K$ та $(N-K)$ модуляційних символів

$$
\begin{aligned}
& \left\{d_{A}^{g}(n)\right\}_{n \in J_{A}^{g}}, n=1, \ldots, N, d_{A}^{g} \in \mathbf{D}\left(M_{A}\right), \\
& \left\{d_{B}^{g}(l)\right\}_{l \in J_{B}^{g}}, l=1, \ldots, N-K, d_{B}^{g} \in \mathbf{D}\left(M_{B}\right),
\end{aligned}
$$

за допомогою яких кожний субблок DM-OFDM-IM створює вектор

$$
\begin{gathered}
\mathbf{d}^{g}=\left[d_{1}^{g}(1) d_{2}^{g}(2) \ldots d_{N_{F}}^{g}(N)\right], f=\left\{1,2, \ldots, N_{F}\right\}, \\
d_{f}^{g}(n)=d_{A}^{g}(n), n \in J_{A}^{g}, \\
d_{f}^{g}(l)=d_{B}^{g}(l), l \in J_{B}^{g} .
\end{gathered}
$$

Після об'єднання субблоків формується загальний вектор сигналів DM-OFDM-IM для пари передавальних антен:

$$
\mathbf{d}\left(J^{g}, d_{f}^{g}(n), d_{f}^{g}(l)\right)=\left[d_{1}(1) d_{2}(2) \ldots d_{N_{F}}(N)\right] .
$$

Просторово-частотний кодер Аламоуті забезпечує передачу з двох антен $T x$ кожної пари модуляційних символів одного типу ( $A$ чи $B)$ зі складу $\mathbf{d}$ на двох сусідніх піднесучих $f$ та $f+1, f=\left\{1, \ldots, N_{F}\right\}$. Таким чином, синтезуються два вектори

$$
\begin{aligned}
& \mathbf{d}_{1}=\left[d_{1}(1)-d_{2}^{*}(2) d_{3}(3)-d_{4}^{*}(4) \ldots d_{N_{F}-1}(N-1)-d_{N_{F}}^{*}(N)\right],
\end{aligned}
$$

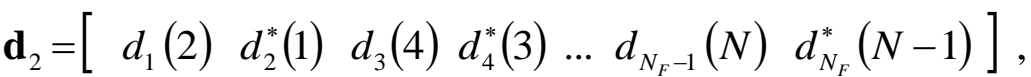

\begin{tabular}{|c|c|c|c|}
\hline $\begin{array}{c}\text { Індексні } \\
\text { біти }\end{array}$ & $\begin{array}{c}\text { Індекси піднесучих, } \\
\text { активовані для } \\
\text { передачі ансамблів } \\
\text { сигналів типу } A\end{array}$ & $\begin{array}{c}\text { Індекси піднесучих, } \\
\text { активовані для } \\
\text { передачі ансамблів } \\
\text { сигналів типу } B\end{array}$ & $\begin{array}{c}\text { Структура субблоків } \\
\text { DM-OFDM-IM на виході кодера } \\
\text { SFBC для двох передавальних } \\
\text { антен } \\
\end{array}$ \\
\hline 0 & $\{1,2\}$ & $\{3,4\}$ & 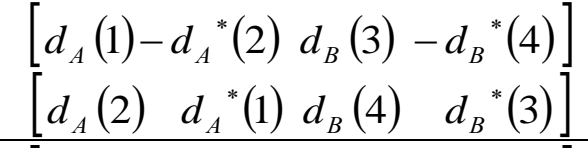 \\
\hline 1 & $\{3,4\}$ & $\{1,2\}$ & 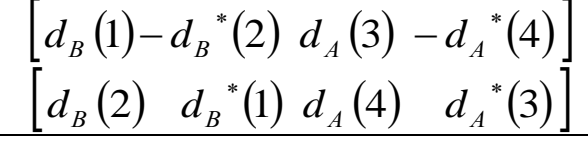 \\
\hline
\end{tabular}

причому вектор $\mathbf{d}_{1}$ сформований для передачі першою антеною $T x_{1}$, a $\mathbf{d}_{2}$ - для $T x_{2}$.

Реалізація інформаційно-керованого механізму активації піднесучих в субблоці $G$ для випадку $N=4, K=2$ наведена у табл. 1. Оскільки SFBC в умовах частотної селективності потребує використання лише пари суміжних піднесучих, то комбінації $\{1,3\},\{2,4\},\{1,4\}$ не задовольняють умову рівномірності амплітудно-частотної характеристики (АЧХ) та лінійності фазо-частотної характеристики (ФЧХ) на тривалості просторово-частотного кодового слова.

Таблиця 1 - Варіант RLUT для $N=4, K=2, p_{1}=1$

Після виконання процедури IFFT, формування пілот-сигналів, додавання циклічного префіксу СР (Cyclic Prefix), паралельно-послідовного (Parallel-to-Serial, P/S) та цифро- 
аналогового перетворення (ЦАП) здійснюється одночасна передача DM-OFDM-IM сигналів за допомогою пари антен $T x_{1}$ та $T x_{2}$.

На приймальній стороні після прямого швидкого перетворення Фур'є (FFT) на вході просторово-частотного декодера формується сигнальний вектор

$$
\mathbf{r}=\mathbf{H}_{1} \mathbf{d}_{1}+\mathbf{H}_{2} \mathbf{d}_{2}+\mathbf{w},
$$

де

$\mathbf{H}_{i}=\operatorname{diag}\left[\left|H_{1}\right|_{i}^{2}\left|H_{2}\right|_{i}^{2} \ldots\left|H_{N_{F}}\right|_{i}^{2}\right], i=\{1,2\}$ - діагональна матриця з елементами, що визначають частотну характеристику кожного з $N_{F}$ підканалів $i$-ої антени;

$\mathbf{w}$ - вектор значень адитивного білого гаусівського шуму (Additive White Gaussian Noise, AWGN).

Вихідні сигнали декодера SFBC для кожної пари суміжних піднесучих $f$ та $f+1$

$$
\begin{aligned}
& r_{f}=H_{1, f} d_{f}+H_{2, f} d_{f+1}+w_{f}, \\
& r_{f+1}=-H_{1, f+1} d_{f+1}^{*}+H_{2, f+1} d_{f}^{*}+w_{f+1},
\end{aligned}
$$

3 урахуванням припущення щодо ідентичності просторово-частотного кодового слова в межах одного символу OFDM ( $H_{1, f}=H_{1, f+1}$ та $\left.H_{2, f}=H_{2, f+1}\right)$, використовуються для детектування сигналу шляхом виконанням лінійних операцій зі збереженням максимального порядку рознесення:

$$
\begin{aligned}
& z_{f}=H_{1, f}^{*} r_{f}+H_{2, f} r_{f+1}^{*}, \\
& z_{f+1}=H_{2, f}^{*} r_{f}-H_{1, f} r_{f+1}^{*} .
\end{aligned}
$$

Після обчислення канальних коефіцієнтів для кожної пари суміжних піднесучих детектор максимальної правдоподібності ML формує оцінки комплексних символів $d_{A}^{g} \in \mathbf{D}\left(M_{A}\right)$ та активованого набору піднесучих $J_{A}^{g}(k)$ для кожного субблоку за допомогою метрики

$$
\hat{\mathbf{d}}^{g}\left(\hat{J}_{A}^{g}, \hat{d}_{A}^{g}\right)=\arg \min _{J_{A}^{g}, d_{A}^{g}} \sum_{k=1}^{N}\left|\mathbf{z}_{k}^{g}-\mathbf{H}_{k}^{g} \quad \mathbf{d}_{A, k}^{g}\right|^{2} .
$$

У (3) $\mathbf{z}_{k}^{g}$ - оцінки отриманих сигналів у кожному субблоці $g$;

$\mathbf{H}_{k}^{g} \quad$ - частотна характеристика підканалів $g$-го субблоку;

$\mathbf{d}_{A, k}^{g}$ - вектор переданого сигналу, що складається з модуляційних символів типу $A$.

Після детектування піднаборів $J_{A}^{g}$ та відповідних їм модуляційних символів $\mathbf{D}\left(M_{A}\right)$ на основі RLUT визначаються піднабори $J_{B}^{g}$ та символи $\mathbf{D}\left(M_{B}\right)$.

Обчислювальна складність реалізації ML-детектора за кількістю операцій комплексного множення становить $O\left(C\left(\begin{array}{l}N \\ K\end{array}\right) M_{A}^{N} M_{B}^{N-K}\right)$ для кожного субблоку, що демонструє неможливість його практичного застосування при великих значеннях розмірів ансамблю сигналів $M$ та субблоку $N$. У таких випадках часто використовуються субоптимальні алгоритми детектування, що окремо визначають індексні та модуляційні біти, через що втрачається ЕЕ.

Запропонований метод SFBC-DM-OFDM-IM 3 ядром Аламоуті забезпечує CE $\left[б і \mathrm{i} / \mathrm{c} / \Gamma_{ц}\right]$ (тут і в подальшому для спрощення та зрозумілості рисунків та формул, пов'язаних із розрахунком спектральної ефективності, величину циклічного префіксу СР не враховано)

$$
\eta_{\text {SFBC-DM-OFDM-MM }}=\frac{\left\lfloor\log _{2}\left(C\left(\begin{array}{l}
N \\
K
\end{array}\right)\right)\right\rfloor+K \log _{2} M_{A}+(N-K) \log _{2} M_{B}}{N} .
$$


Очевидно, що підвищувати загальну СЕ можливо збільшенням кількості індексних біт за рахунок формування субблоків великого розміру, проте у [21] показано, що при $N>8$ складність ML-детектора зростає експоненційно, через що компромісним рішенням для забезпечення високої інформаційної ефективності запропонованого методу є використання невеликих значень $N$ та $M$. Слід зауважити, що максимальна кількість біт $p_{1}$ досягається при $K=N / 2$.

Для параметрів $N=4, K=2, \mathbf{D}\left(M_{A, B}\right) \in\{$ BPSK, QPSK $\}, \quad$ що представляють практичний інтерес, можлива реалізація оптимального ML-детектора на базі сучасних цифрових процесорів обробки сигналів. Оскільки для $N=4, K=2$ умову ідентичності просторово-частотного кодового слова задовольняють лише пари піднесучих $\{1,2\}$ та $\{3,4\}$, маємо

$$
\eta_{\text {SFBC-DM-ОFDM-IM }}=\frac{1+K \log _{2} M_{A}+(N-K) \log _{2} M_{B}}{N} .
$$

Результати моделювання. Оцінку адекватності та ефективності запропонованого методу проведено з використанням пакету Simulink у середовищі моделювання MATLAB. Узагальнені параметри безпроводових систем передачі інформації, що моделюються, наведено в табл. 2. Зазначені характеристики каналів $є$ найбільш типовими для сучасних СБ3 і близькі до моделей, що розглядаються в [22], [23] та рекомендаціях [24] - [26]. Завмирання в каналі згенеровано за допомогою моделі Джейкса, що широко застосовується для опису нестаціонарних релеївських завмирань; коефіцієнти підсилення променів $є$ незалежними гаусівськими випадковими змінними. Вважаємо оцінку параметрів каналів та систему синхронізації ідеальними. Величина використаного для моделювання середньоквадратичного значення затримки $\tau$ характеризує канал 3 помірною частотною селективністю. Значення нормованого доплерівського зсуву частот $F_{\text {д }}=f_{\text {д }} \cdot T_{\text {symb }}=0,013 \ldots 0,026$ (де $f_{\text {д }}=50 \ldots 250$ Гц - доплерівський зсув частот) відповідають швидкості руху мобільної станції (МС) 30...300 км/год для значення несучої частоти 512 МГц.

Таблиця 2 - Узагальнені параметри моделювання систем MIMO-OFDM

\begin{tabular}{|c|c|}
\hline Кількість піднесучих ОFDM, $N_{F}$ & 512 \\
\hline Частотний інтервал між піднесучими, $\Delta f$ & 10,9375 кГц \\
\hline Тривалість ОFDМ символу, $T_{\text {sуmb }}$ & 102,86 мкс \\
\hline Частота дискретизації, $f_{s}$ & $2,8 \mathrm{MГц}$ \\
\hline Кількість променів, $L$ & 6 \\
\hline Коефіціснти підсилення променів, дБ & {$[-2.5,0,-3,-5,-2,-4]$} \\
\hline Затримки променів, мкс & {$[0,0.3,1.0,1.6,5.0,6.6]$} \\
\hline Середньоквадратичне значення затримки $\tau$ в каналі & 3,48 мкс \\
\hline Доплерівський зсув частот, $f_{\text {д }}$ & $50 \ldots 250$ Гц \\
\hline Значення нормованого доплерівського зсуву частот, $F_{\text {д }}$ & {$[0 \ldots 0,026]$} \\
\hline Види модуляції & ВРSK, QPSK \\
\hline Схеми МІМО $T x \times R x$ & $2 \times 1,2 \times 2$ \\
\hline
\end{tabular}

При моделюванні методи 3 дворежимною індексною модуляцією використовуються оптимізовані за показниками ймовірності умовної попарної помилки (Conditional Pairwise Error Probability, CPEP) модифіковані ансамблі сигналів BPSK та QPSK, запропоновані у [18]: 


$$
\begin{gathered}
\text { BPSK }-\mathbf{D}\left(M_{A}\right)=\{1,-1\} \text { та } \mathbf{D}\left(M_{B}\right)=\{j,-j\} . \\
\text { QPSK }-\mathbf{D}\left(M_{A}\right)=\{0,7+0,7 j ;-1,3+0,7 j ;-1,3-1,3 j ; 0,7-1,3 j\} \text { та } \\
\mathbf{D}\left(M_{B}\right)=\{1,3+1,3 j ;-0,7+1,3 j ;-0,7-0,7 j ; 1,3-0,7 j\} .
\end{gathered}
$$

Слід зазначити, що для 16-QАМ таку модифіковану пару також описано у [18]. Вона дає виграш за СЕ до 12,5\% порівняно з однорежимними методами OFDM-IM (з однаковими структурами субблоків) за рахунок зменшеного ЕВ, проте кількість обчислень у такому випадку не дає можливості реалізації оптимального ML-детектора. Важливо зауважити, що запропоновані пари комплексних ансамблів сигналів забезпечують аналогічні ймовірності помилкового детектування індексних біт та біт модуляційних ансамблів сигналів як і у схемах OFDM-IM, де активні піднесучі модулюються класичними BPSK, QPSK та 16-QAM. Відсутність відомих варіантів оптимізованих пар ансамблів сигналів для $M>16$ варто пояснювати несуттєвим внеском концепції IM (кількості індексних біт) у загальну СЕ таких систем, незважаючи на потенційну можливість використання ансамблів $M=32,64, \ldots$ при сприятливій завадовій обстановці ( $S N R>30$ дБ).

Аналіз кривих рис. 2 показує, що при $F_{\text {д }}=0$ для зазначеного рівня частотної селективності ( $\tau=3,48$ мкс) методи, в основі яких лежить просторово-частотне блочне кодування SFBC, суттєво програють за показниками завадостійкості методам з STBC через свою критичність до нерівномірності АЧХ та нелінійності ФЧХ каналу на суміжних піднесучих. Дворежимна IM забезпечує перевагу за показниками CE у порівнянні 3 класичними та однорежимними індексними методами STBC та SFBC для представляючих практичний інтерес $M$. Для компактності надалі для дворежимних методів SFBC та STBC вважаємо структуру субблоку $N=4, K=2$ стандартною. Важливо, що з усіх методів SFBC для $S N R>13$ дБ найбільш завадостійким $€ \operatorname{SFBC-OFDM-IM}(4,2)$, проте його CE $(\eta=$ 0,75 біт/с/Гц) $\epsilon$ низькою через вимкнення 3 передачі половини піднесучих, тому він неспроможний конкурувати 3 рештою методів, проаналізованих у даній статті, для фіксованого $M$, через що надалі не розглядається. Криві завадостійкості індексних методів SFBC практично співпадають при $S N R<10$ дБ через однаковий рівень ймовірності помилкового детектування одного індексного біту для обох методів. Енергетичний виграш (EB) методу SFBC-DM-OFDM-IM у порівнянні 3 класичним SFBC складає 4 дБ для ймовірності бітової помилки $P_{\text {пом }}=10^{-5}$. Завадостійкість та СЕ методів на базі $\mathrm{STBC} 3$ OFDM-IM для різної кількості активованих піднесучих у субблоці детально досліджено та описано у [19].

Збільшення кількості приймальних антен покращує завадостійкість систем передачі інформації та дає можливість збільшувати СЕ шляхом використання ансамблів сигналу більшого розміру в умовах обмеженості енергетичних ресурсів. Аналіз кривих на рис. 3 демонструє негативний вплив збільшення рівня нестаціонарності каналу як на класичний SFBC, так і на індексні варіанти SFBC та STBC. Завадостійкість STBC-DM-OFDM-IM $\epsilon$ кращою лише для незначних значень ДЗЧ, а при $F_{\text {д }} \geq 0,026$ очевидною $є$ критичність даного методу до рівня часової селективності в каналі. Слід зазначити, що виграш STBC-DM-OFDM-IM за CE становить 10-20\% порівняно 3 індексним та базовим SFBC, відповідно.

Метод SFBC-DM-OFDM-IM дає ЕВ близько 2 дБ (при $P_{n o м}=10^{-3}$ ) у порівнянні 3 класичним $\mathrm{SFBC}$ при $F_{\text {д }}=0 \ldots 0,013$. Подальше підвищення рівня нестаціонарності призводить до зменшення завадостійкості обох схем SFBC з незначним ЕВ індексного варіанту. Таким чином, при зростанні рівня нестаціонарності каналу $\left(F_{\text {д }}>0,01\right)$ доцільно застосовувати метод SFBC-DM-OFDM-IM, що забезпечує при $P_{n о м}=10^{-3}$ ЕВ близько 2 дБ та виграш за СЕ до 6-20\% порівняно з класичним SFBC (20\% при BPSK, 11\% при QPSK та 6\% 
при 16-QAM).

Вибір конфігурацій МIMO $2 \times 1$ та $2 \times 2$ гарантує мінімальні масо-габаритні показники мобільних станцій при забезпеченні необхідного рівня декореляції антен, що важливо для оперативного та ефективного виконання завдань у сучасних СБЗ.

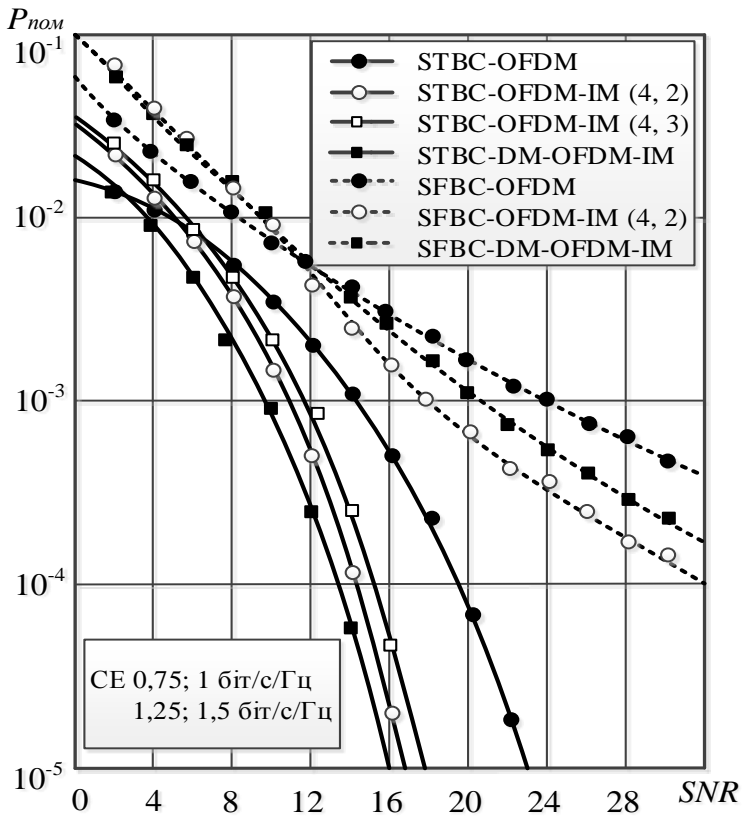

Рисунок 2 - Завадостійкість класичних та індексних варіантів методів STBC і SFBC, BPSK, $2 \times 1, F_{\text {д }}=0$

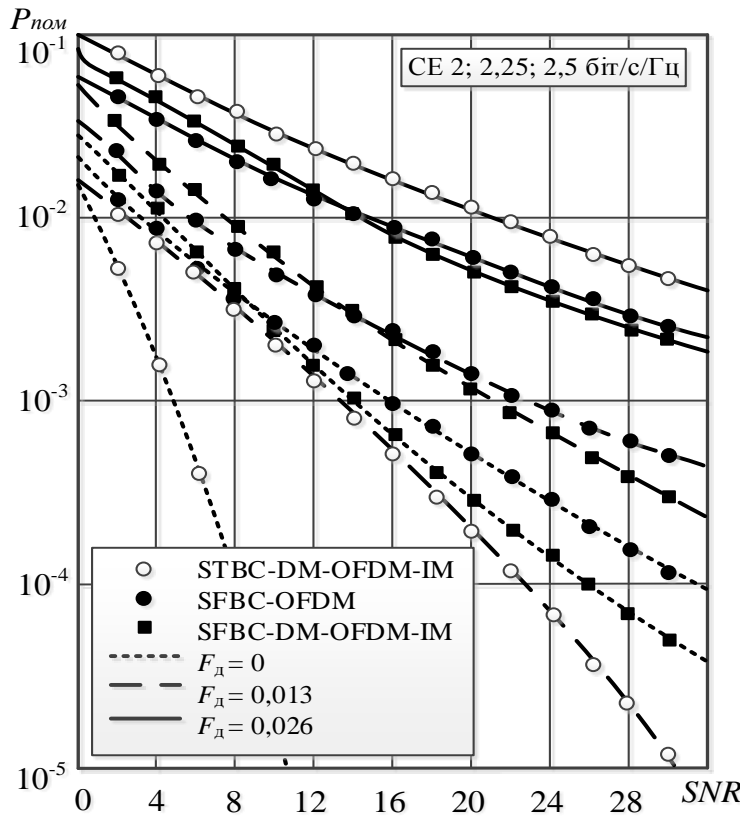

Рисунок 3 - Завадостійкість класичних та індексних варіантів методів STBC і SFBC,

QPSK, $2 \times 2, F_{\text {д }}=0 \ldots 0,026$

Висновки. Запропонована сигнально-кодова конструкція із об'єднанням дворежимної індексної модуляції піднесучих OFDM та ортогонального просторово-частотного блочного кодування SFBC-DM-OFDM-IM з ядром Аламоуті дає можливість підвищити спектральну та енергетичну ефективність класичного методу SFBC-OFDM. У порівнянні з SFBC-OFDM застосування такої СКК забезпечує для $P_{n o м}=10^{-4}$ ЕВ до 4 дБ та одночасне підвищення СЕ до 6-20\% для ансамблів сигналів невеликого об'єму. Запропонований метод рекомендовано застосовувати в каналах 3 переважаючою часовою селективністю та помірним рівнем частотної селективності, що дає можливість організації якісного зв'язку 3 високодинамічними наземними об'єктами чи літальними апаратами різного призначення. Метод може ефективно використовуватися у технологіях безпроводового зв'язку нового покоління, а також в сучасних безпроводових мережах зв'язку, що потребують реалізації об'ємних мультимедійних додатків зі СЕ до 4,25 біт/с/Гц в умовах обмеженості просторовоенергетичних ресурсів.

Для забезпечення можливості виготовлення компактних радіостанцій $з$ лімітованою складністю реалізації та з метою отримання максимальної інформаційної ефективності при використанні запропонованого методу SFBC-DM-OFDM-IM доцільно обмежитись такими параметрами:

$$
N=4, K=2, R \leq T=2, \mathbf{D}(M)=\{B P S K, Q P S K\} .
$$

Перспективним напрямком подальших досліджень $є$ підвищення спектральної ефективності запропонованого методу SFBC-DM-OFDM-IM за рахунок збільшення кількості індексних біт шляхом забезпечення інваріантності даного методу до нерівномірності АЧХ та 
нелінійності ФЧХ для будь-якої комбінації пар піднесучих у субблоці.

\section{СПИСОК ВИКОРИСТАНИХ ДЖЕРЕЛ}

[1] М.Г. Бакулин, Л.А. Варукина, и В.Б. Крейнделин, “Технология МІМО. Приниипь и алгоритмыl," Москва, Российская Федерация, Горячая линия-Телеком, 244 C, 2014.

[2] L. Hanzo, Y.(J.) Akhtman, L. Wang, and M. Jiang, "MIMO-OFDM for LTE, WiFi and WiMax. Coherent versus non-coherent and cooperative turbo-transceivers," UK: J.W.S., 658 P, 2011.

[3] J. Andrews, A. Ghosh, and M. Rias, "Fundamentals of WiMAX: understanding broadband wireless networking (Prentice Hall Communications Engineering and Emerging Technologies Series)," Pearson Education. Prentice Hall, USA, 449 P, 2007.

[4] E. Dahlman, S. Parkvall, and J. Skold, "4G: LTE/LTE-advanced for mobile broadband," Academic press, $431 \mathrm{P}, 2013$.

[5] S. Alamouti "A simple transmit diversity technique for wireless communications," IEEE Journal on Select Areas in Communications, vol. 16, no. 8, pp. 1451-1458, 1998, doi: 10.1109/49.730453.

[6] C. Li, G. Li, and H. Liu, "Performance comparison of the STBC-OFDM decoders in a fast fading channel," Journal of Marine Science and Technology, vol. 20, no. 5, pp. 534-540, 2012, doi: 10.6119/JMST-011-0506-3.

[7] M. Youssefi, N. Bounouader, Z. Guennoun, and J. Abbadi, "Adaptive Switching between Space-Time and Space-Frequency Block Coded OFDM Systems in Rayleigh Fading Channel," International Journal of Communications, Network and System Sciences, vol. 6, pp. 316-323, 2013, doi: 10.4236/IJCNS.2013.66034.

[8] 3GPP TS 36.211 Evolved Universal Terrestrial Radio Access (E-UTRA); Physical Channels and Modulation (Release 8), 2009.

[9] E. Basar, "Index modulation techniques for 5G wireless networks," IEEE Communications Magazine, vol. 54, no. 7, pp. 168-175, 2016, doi: 10.1109/MCOM.2016.7509396.

[10] M. Wen, X. Cheng, and L. Yang, "Index Modulation for 5G Wireless Communications," Springer International Publishing, 52 P, 2017, doi: 10.1007/978-3-319-51355-3_1.

[11] E. Basar, M. Wen, R. Mesleh, M. Renzo, Y. Xiao, and H. Haas, "Index Modulation Techniques for Next-Generation Wireless Networks," Special section on index modulation techniques for next-generation wireless networks. IEEE Access, vol. 5, pp. 16693-16746, 2017, doi: 10.1109/ACCESS.2017.2737528.

[12] X. Cheng, M. Zhang, M. Wen, and L. Yang, "Index Modulation for 5G: Striving to Do More with Less," IEEE Wireless Communications, vol. 25, no. 2, pp. 126-132, 2018, doi: 10.1109/MWC.2018.1600355.

[13] E. Basar, U. Aygolu, P. Erdal, and V. Poor, "Orthogonal frequency division multiplexing with index modulation," IEEE Transactions on Signal Processing, vol. 16, no. 22, pp. 5536-5549, 2013, doi: 10.1109/GLOCOM.2012.6503868.

[14] M. Wen, X. Cheng, M. Ma, B. Jiao, and V. Poor, "On the achievable rate of OFDM with index modulation," IEEE Transactions on Signal Processing, vol. 64, no. 8, pp. 1919-1932, 2016, doi: 10.1109/TSP.2015.2500880.

[15] E. Basar, U. Aygolu, and E. Panayirci, "Orthogonal frequency division multiplexing with index modulation in the presence of high mobility," IEEE International Black Sea Conference on Communications and Networking, pp. 147-151, 2012, doi: 10.1109/BlackSeaCom.2013. 6623399.

[16] М.I. Науменко, та В.І. Солодовник, “Сигнально-кодові конструкції 3 індексною модуляцією піднесучих OFDM та просторово-часовим блочним кодуванням для частотно-селективних та нестаціонарних каналів безпроводового зв'язку,” Електронне наукове фахове видання “Проблеми телекомунікацій”, Харківський Національний Університет Радіоелектроніки, Збірник №2 (25), Харків, Україна, 2019.

[17] В.I. Солодовник, "Методи просторово-часового блочного кодування 3 індексною модуляцією піднесучих OFDM для частотно-селективних та нестаціонарних каналів 
безпроводового зв'язку,” ХІІІ Міжнародна науково-технічна конференція "Перспективи телекомунікацій" ПТ-2019: Збірник матеріалів конференції, КПІ ім. Ігоря Сікорського, Київ, Україна, сс. 153-155, 2019.

[18] K.-H. Kim, and P. Hosung, "New Design of Constellation and Bit Mapping for Dual Mode OFDM-IM," IEEE Access, vol. 7, pp. 52573-52580, 2019, doi: 10.1109/ACCESS.2019. 2912704.

[19] М.I. Науменко, В.І. Солодовник, та Л.М. Погребняк, “Метод просторово-часового блочного кодування 3 дворежимною індексною модуляцією піднесучих OFDM для частотно-селективних каналів безпроводового зв'язку," Збірник наукових пращь BITI, Київ, Україна, Том №2, сс. 53-60, 2019.

[20] M.I. Науменко, та B.I. Солодовник, "Signal-Code Construction Based on Space-Time Block Coding with Dual-Mode Index Modulation Aided OFDM," IEEE науково-практична конференція "Проблеми інфокомунікацій. Наука і технологї (PIC S\&T)", Київ, Україна, Том №1, сс. 57-62, 2019.

[21] T. Mao, Z. Wang, Q. Wang, S. Chen, and L. Hanzo, "Dual-mode index modulation aided OFDM," IEEE Access, vol. 5, pp. 50-60, 2017, doi: 10.1109/ACCESS.2016.2601648.

[22] K. Fazel, and S. Kaiser, "Multi-carrier and spread spectrum systems: Second Edition," WILEY, 360 P, 2008.

[23] F. Kalbat, A. Al-Dweik, B. Sharif, and G. Karagiannidis, "Robust Precoded MIMO-OFDM for Mobile Frequency-Selective Wireless Channels," IEEE Wireless Conference and Networking Conference (WCNC). Track 1: PHY and Fundamentals, 6 P, 2016, doi: 10.1109/WCNC. 2016.7564880.

[24] Physical layer aspects for evolved Universal Terrestrial Radio Access (UTRA) (Rel. 7). Third-Generation Partnership Project; Technical Specification Group Radio Access Network; Technical Report 3GPP TR 25.814 V7.1.0 (2006-09).

[25] LTE; Evolved Universal Terrestrial Radio Access (E-UTRA); Base Station (BS) radio transmission and reception (3GPP TS 36.104 version 8.2.0 Release 8). Technical Specification, ETSI TS 136104 V8.2.0 (2008-11).

[26] ETSI TS 136104 V8.2.0 (2008-11).

Стаття надійшла до редакції 30.09.2019.

\section{REFERENCE}

[1] M.G. Bakulin, L.A. Varukina, and V.B. Krejndelin, "Tehnologija MIMO. Principy $i$ algoritmy,” Moskow, Russian Federation, Gorjachaja linija-Telekom, 244 P, 2014.

[2] L. Hanzo, Y.(J.) Akhtman, L. Wang, and M. Jiang, "MIMO-OFDM for LTE, WiFi and WiMax. Coherent versus non-coherent and cooperative turbo-transceivers," UK: J.W.S., 658 P, 2011.

[3] J. Andrews, A. Ghosh, and M. Rias, "Fundamentals of WiMAX: understanding broadband wireless networking (Prentice Hall Communications Engineering and Emerging Technologies Series)," Pearson Education. Prentice Hall, USA, 449 P, 2007.

[4] E. Dahlman, S. Parkvall, and J. Skold, "4G: LTE/LTE-advanced for mobile broadband," Academic press, 431 P, 2013.

[5] S. Alamouti, "A simple transmit diversity technique for wireless communications," IEEE Journal on Select Areas in Communications, vol. 16, no. 8, pp. 1451-1458, 1998, doi: 10.1109/49.730453.

[6] C. Li, G. Li, and H. Liu, "Performance comparison of the STBC-OFDM decoders in a fast fading channel," Journal of Marine Science and Technology, vol. 20, no. 5, pp. 534-540, 2012, doi: 10.6119/JMST-011-0506-3.

[7] M. Youssefi, N. Bounouader, Z. Guennoun, and J. Abbadi, "Adaptive Switching between Space-Time and Space-Frequency Block Coded OFDM Systems in Rayleigh Fading Channel," International Journal of Communications, Network and System Sciences, vol. 6, 
pp. 316-323, 2013, doi: 10.4236/IJCNS.2013.66034.

[8] 3GPP TS 36.211 Evolved Universal Terrestrial Radio Access (E-UTRA); Physical Channels and Modulation (Release 8), 2009.

[9] E. Basar, "Index modulation techniques for 5G wireless networks," IEEE Communications Magazine, vol. 54, no. 7, pp. 168-175, 2016, doi: 10.1109/MCOM.2016.7509396.

[10] M. Wen, X. Cheng, and L. Yang, "Index Modulation for 5G Wireless Communications," Springer International Publishing, 52 P, 2017, doi: 10.1007/978-3-319-51355-3_1.

[11] E. Basar, M. Wen, R. Mesleh, M. Renzo, Y. Xiao, and H. Haas, "Index Modulation Techniques for Next-Generation Wireless Networks," Special section on index modulation techniques for next-generation wireless networks. IEEE Access, vol. 5, pp. 16693-16746, 2017, doi: 10.1109/ACCESS.2017.2737528.

[12] X. Cheng, M. Zhang, M. Wen, and L. Yang, "Index Modulation for 5G: Striving to Do More with Less," IEEE Wireless Communications, vol. 25, no. 2, pp. 126-132, 2018, doi: 10.1109/ MWC.2018.1600355.

[13] E. Basar, U. Aygolu, P. Erdal, and V. Poor, "Orthogonal frequency division multiplexing with index modulation," IEEE Transactions on Signal Processing, vol. 16, no. 22, pp. 5536-5549, 2013, doi: 10.1109/GLOCOM.2012.6503868.

[14] M. Wen, X. Cheng, M. Ma, B. Jiao, and V. Poor, "On the achievable rate of OFDM with index modulation," IEEE Transactions on Signal Processing, vol. 64, no. 8, pp. 1919-1932, 2016, doi: 10.1109/TSP.2015.2500880.

[15] E. Basar, U. Aygolu, and E. Panayirci, "Orthogonal frequency division multiplexing with index modulation in the presence of high mobility," IEEE International Black Sea Conference on Communications and Networking, pp. 147-151, 2012, doi: 10.1109/BlackSeaCom.2013. 6623399.

[16] M.I. Naumenko, and V.I. Solodovnick, "Cy'gnal'no-kodovi konstrukciyi z indeksnoyu modulyaciyeyu pidnesuchy`kh OFDM ta prostorovo-chasovy`m blochny`m koduvannyam dlya chastotno-selekty`vny`kh ta nestacionarny`kh kanaliv bezprovodovogo zv'yazku [Signalcode constructions based on index modulation aided OFDM and space-time block coding for frequency-selective and time varying wireless communication channels]." Elektronne naukove fakhove vy'dannya "Problemy" telekomunikacij" [Problems of Telecommunications], Kharkivs`ky`j Nacional'ny`j Universy`tet Radioelektroniky, vol. 2 (25), Kharkiv, Ukraine, 2019. (In Ukrainian).

[17] V.I. Solodovnick, "Metody' prostorovo-chasovogo blochnogo koduvannya z indeksnoyu modulyaciyeyu pidnesuchy`kh OFDM dlya chastotno-selekty`vny`kh ta nestacionarny`kh kanaliv bezprovodovogo zv'yazku [Methods of space-time block coding with OFDM subcarrier index modulation for frequency-selective and time varying wireless communication channels]," in Zbirny`k materialiv Try`nadcyatoyi Mizhnarodnoi naukovo-tekhnichnoi konferenciyi "Perspekty`vy telekomunikacij» PT-2019, KPI im. Igorya Sikors`kogo [Proceedings of the Thirteenth International Scientific and Technical Conference "Modern Challenges In Telecommunications" MCT-2019, Igor Sikorsky Kyiv Polytechnic Institute], Kyiv, Ukraine, pp. 153-155, 2019. (In Ukrainian).

[18] K.-H. Kim, and P. Hosung, "New Design of Constellation and Bit Mapping for Dual Mode OFDM-IM," IEEE Access, vol. 7, pp. 52573-52580, 2019, doi: 10.1109/ACCESS.2019. 2912704.

[19] M.I. Naumenko, V.I. Solodovnick, and L.M. Pohrebniak "Metod prostorovo-chasovogo blochnogo koduvannya $\mathrm{z}$ dvorezhy`mnoyu indeksnoyu modulyaciyeyu pidnesuchy`x OFDM dlya chastotno-selekty`vny`x kanaliv bezprovodovogo zv'yazku [Method of Space-Time Block Coding with Dual-Mode OFDM Subcarriers Index Modulation for Frequency-Selective Wireless Communication Channels]," Zbirny`k naukovy`x pracz'VITI, [Collection of research papers of MITI], Kyiv, Ukraine, vol. 2, pp. 53-60, 2019. (In Ukrainian). 
[20] M.I. Naumenko, and V.I. Solodovnick, "Signal-Code Construction Based on Space-Time Block Coding with Dual-Mode Index Modulation Aided OFDM," IEEE International Scientific and Practical Conference Problems of infocommunications. Science and technology PIC S\&T, Kyiv, Ukraine, vol. 1, pp. 57-62, 2019.

[21] T. Mao, Z. Wang, Q. Wang, S. Chen, and L. Hanzo, "Dual-mode index modulation aided OFDM," IEEE Access, vol. 5, pp. 50-60, 2017, doi: 10.1109/ACCESS.2016.2601648.

[22] K. Fazel, S. Kaiser "Multi-carrier and spread spectrum systems: Second Edition," WILEY, 360 P, 2008.

[23] F. Kalbat, A. Al-Dweik, B. Sharif, and G. Karagiannidis, "Robust Precoded MIMO-OFDM for Mobile Frequency-Selective Wireless Channels," IEEE Wireless Conference and Networking Conference (WCNC). Track 1: PHY and Fundamentals, 6 P, 2016, doi: 10.1109/WCNC. 2016.7564880.

[24] Physical layer aspects for evolved Universal Terrestrial Radio Access (UTRA) (Rel. 7). Third-Generation Partnership Project; Technical Specification Group Radio Access Network; Technical Report 3GPP TR 25.814 V7.1.0 (2006-09).

[25] LTE; Evolved Universal Terrestrial Radio Access (E-UTRA); Base Station (BS) radio transmission and reception (3GPP TS 36.104 version 8.2.0 Release 8). Technical Specification, ETSI TS 136104 V8.2.0 (2008-11).

[26] ETSI TS 136104 V8.2.0 (2008-11).

VYACHESLAV SOLODOVNICK, MYKOLA NAUMENKO

\section{METHOD OF SPACE-FREQUENCY BLOCK CODING WITH DUAL-MODE INDEX MODULATION AIDED OFDM}

The technology of combining Multiple Input-Multiple Output (MIMO) and Orthogonal Frequency Division Multiplexing (OFDM) for modern Wireless Communication Systems is considered. The areas of priority use of time and frequency variants of Alamouti's diversity scheme for Wireless Communication Channels with limited frequency and energy resources are determined. The concept of Index Modulation (IM) is analyzed. The method of OFDM subcarriers index modulation is determined as the most promising means of increasing noise immunity and speed of information transmission for real frequency-selective channels of Wireless Communication Systems. The benefits of Dual-Mode OFDM-IM with optimized signal constellations based on BPSK, QPSK and 16-QAM are demonstrated. A novel Signal-Code design combining the Dual-Mode Index Modulation Aided OFDM and the Orthogonal Space-Frequency Block Coding with Alamouti's core SFBC-DM-OFDM-IM is proposed. Compared to classical SFBC-OFDM the proposed method allows simultaneously to improve spectral and energy efficiency of information transmission systems in frequency and time-varying wireless communication channel. The SFBC-DM-OFDM-IM method is advisable for providing high-quality communications with highly dynamic ground objects, unmanned aerial vehicles and other aircrafts in the conditions of Signal-to-Noise Ratio critical reduction, which takes place under the influence of electronic suppression means. The obtained scientific results can be effectively used for designing new generation Wireless Communication Networks with limited frequency and energy resources.

Key words: Space-Frequency Block Coding, MIMO, OFDM, Index Modulation, Dual-Mode, non-stationarity.

Науменко Микола Іванович, доктор технічних наук, професор, професор кафедри транспортних мереж факультету телекомунікаційних систем, Військовий інститут телекомунікацій та інформатизації імені Героїв Крут, Київ, Україна. 
P-ISSN 2411-1031. Information Technology and Security. July-December 2019. Vol. 7. Iss. 2 (13)

ORCID: 0000-0002-4804-5609.

E-mail: teenex60@ukr.net.

Солодовник В'ячеслав Ігорович, ад'юнкт науково-організаційного відділу, Військовий інститут телекомунікацій та інформатизації імені Героїв Крут, Київ, Україна.

ORCID: 0000-0002-9113-7672.

E-mail: teenex@ukr.net.

Naumenko Mykola, doctor of technical sciences, professor, professor of the transport networks department of the telecommunication systems faculty, Military Institute of Telecommunications and Informatization named after Kruti Heroes, Kyiv, Ukraine.

Solodovnick Vyacheslav, adjunct of the scientific-organizational department, Military Institute of Telecommunications and Informatization named after Kruti Heroes, Kyiv, Ukraine. 